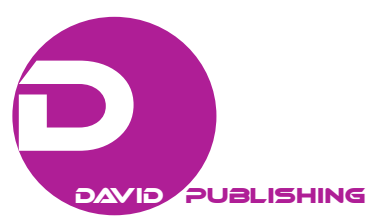

\title{
The Substance of Memory: Plants, Objects, and Affect
}

\author{
John Charles Ryan \\ Edith Cowan University, Perth, Australia
}

\begin{abstract}
The purpose of this article is to develop the concept "botanical memory" through an analysis of interviews conducted with indigenous plant enthusiasts in the biodiverse Southwest corner of Western Australia. The topic of this article can be described as memory-based studies of plant diversity or botanically-focused oral histories; and the method is ethnographic. Attending to the everyday practices constituting botanical memory, the article posits a material-affective framework to foreground the dynamics between plants, people, objects, and remembrance. The writings of Henry David Thoreau and C. Nadia Seremetakis, in conjunction with affect and materiality theory, offer conceptual anchor points for this exploration of human recollection and flora. The interviews indicate that plant-based objects and living plants deepen human memory, particularly through their appeal to touch, taste, smell, and sensation.
\end{abstract}

Keywords: memory, oral history, plants, biodiversity, Henry David Thoreau, C. Nadia Seremetakis, Southwest Australia

\section{Introduction}

On a clear spring afternoon, I follow local conservationist Ian Smith around the rocky outcrops and through the wooded gullies of Mount Matilda in Western Australia (WA). After years of farming the region's flatlands, Ian dedicates his retirement to the promotion and protection of wildflowers-those endemic counterparts of canola and soy. Named the Wheat belt, this six-thousand square mile part of the state lies between metropolitan Perth to the west and the arid Goldfields to the east. Within this predominately agricultural landscape, locales such as Mount Matilda are ecological islands, historically regarded as unsuitable for pastoral activities because of rugged terrain and noxious plants. Regularly on our ascent to the hill's highest point, Ian gestures at flowers with his walking staff-handcrafted from a local tree known as gimlet (Eucalyptus salubris)—as we exchange impressions, ideas, and recollections.

Like the staff, the hill and its plant life bear testimony. All have survived the austerity of the environment and the infelicities of settler history here. The gracefully convoluted walking stick embodies and-indeed—facilitates Ian's attachment to this perduring sanctuary. "The wood is so strong. I've used this staff for years, but there is not much wear. I've stained it with boot polish, and varnished it. That's my name there" ${ }^{\text {.1 }}$. The gimlet staff further points to the material and affective dimensions of human memory developed in this chapter through the concept botanical memory. In previous work, I have defined botanical memory as a form of environmental or place-based memory focused on remembrances of plants; and encompassing

\footnotetext{
John Charles Ryan, Ph.D., Postdoctoral Research Fellow, Edith Cowan University.

1 Ian Smith, interview by John C. Ryan, August 29, 2009, transcript.
} 
individual and collective practices that instigate and sustain such recollections. ${ }^{2}$ In my field interviews with Ian and other floristically-minded individuals, the interconnections between plant materiality-the spikiness, stickiness, smelliness of living plants, as well as the qualities of plant-based objects - and human memory are palpable.

A number of questions have arisen, some of which guide the structure and focus of this chapter. For instance, what is the relationship between plant materiality, human affect, and the manner in which memories are produced, recalled, and enacted? How might memories of plants be elicited before, during, and after a roving conversation in the field, such as ours on Mount Matilda, through material prompts? How do the proximate senses (touch, taste, and smell) especially influence the fidelity and content of botanical memory? In response to these questions, the first part of this chapter formulates a material-affective theory of botanical memory through the work of scholars as historically divergent as naturalist Henry David Thoreau and anthropologist C. Nadia Seremetakis. Following theorist Andrew Jones and extending the precepts of the "material turn”, I argue for a material-affective understanding of botanical remembrance as "dialogic encounter" (Jones, 2007, p. 25) between people, plants, places, and objects.

The chapter's second half historicizes and analyzes ethnographic content, thereby establishing the relevance of the theoretical exegesis to a field-based model of botanical memory. My interview with artist Holly Story reveals her engagement with the edible resin of marri (Corymbia calophylla) for producing works of art in which the endemic tree does the painting. ${ }^{3}$ In another interview with a WA (Western Australia) artist, Nalda Searles, textiles using balga (Xanthorrhoea preissii) embody memories of the plant linked to her creative process. ${ }^{4}$ In comparison, plant propagator Kevin Collins employs banksias (Banksia spp.) parts, particularly their flowers and seed cones, to catalyze memorable experiences for visitors while evoking his own sensory recollections of the small trees. ${ }^{5}$

\section{Background to Botanical Memory: Place and Practice}

The Southwest Australia Ecoregion (or Southwest Botanical Province) is a triangular landmass of 493,000 square kilometers, extending from Shark Bay on the Indian Ocean in the north-west to Israelite Bay on the Southern Ocean in the south-east (Gole, 2006). In the late seventeenth century, the region's botanical uniqueness began to attract naturalists, collectors, and explorers, many of whom were astounded by the plant diversity (Lambers \& Hopper, 2014, pp. xi-xvi). In 1699, William Dampier made the first known collection of Australian plants at Shark Bay, followed in 1791 by Archibald Menzies at King George Sound, now Albany (Lambers \& Hopper, 2014, p. xii). Modern botanists estimate that close to 8,000 plant species exist in the Southwest - a remarkable quantity, considering that one-third have been taxonomically identified only since 1970 (Hopper \& Gioia, 2004, p. 623). Moreover, thirty-five percent of the plants are endemic-occurring nowhere else in a freely growing, uncultivated state. Accordingly, the region has been acknowledged as a "biodiversity hotspot”, defined as a place where "exceptional concentrations of endemic species are undergoing exceptional loss of habitat” (Myers, 2000, p. 853).

\footnotetext{
${ }^{2}$ See John C. Ryan. (2012), Green Sense: The Aesthetics of Plants, Place and Language, especially chapter 8; although outside the scope of my discussion, "botanical memory banking" has been defined by anthropologists as "the systematic documentation [...] of indigenous practices of local farmers associated with traditional varieties of staple and supplementary crops” (Nazarea, 1998, p. 5).

${ }^{3}$ Holly Story, interview by John C. Ryan, May 1, 2014, transcript.

4 Nalda Searles, interview by John C. Ryan, April 8, 2014, transcript.

${ }^{5}$ Kevin Collins, interview by John C. Ryan, September 9, 2009, transcript.
} 
Despite its historical renown, by the year 2000, a meager ten percent of the original 300,000 square kilometers of Southwest vegetation remained (Myers, 2000, p. 854). Of critical importance to conservation of extant diversity is the botanically-rich kwongan, an Aboriginal term denoting the unique sandplain vegetation (Pate \& Beard, 1984). Mount Matilda, the site of my perambulatory conversation with Ian, is ensconced there. Cleared intensively for agriculture and pasture, the three percent of the sandplain vegetation that now remains is threatened by dryland salinity, plant disease, invasive species, and habitat fragmentation (Lambers \& Hopper, 2014, p. xiv). Botanists Stephen Hopper and Paul Gioia assert that "fundamental changes in attitudes toward land use and the intrinsic value of plant life are needed to go hand in hand with a commitment to protect, repair, and restore native vegetation in the face of uncertainty" (2004, p. 644).

Reflecting their entreaty to foster the appreciation of "intrinsic value", a few initiatives have been created to promote the cultural heritage of the region's plant life. ${ }^{6}$ These projects define the heritage of southwest flora through the myriad ways in which plants inspire individuals and communities across time (Ryan, 2014, pp. 49-58). Nonetheless, while the scientific significance of the flora is well-articulated and supported, ${ }^{7}$ expressions of the impact of plants on WA (Western Australia) culture in the past, present, and future remain dispersed across heterogeneous sources: letters, journals, newspaper articles, blogs, websites, poetry, novels, plays, performances, paintings, photographs, sculptures, crafts-and the memory-rich narratives of activists, artists, conservationists, scientists, tourists, and other plant enthusiasts. The latter is a vital, though relatively unprobed, facet of the southwest flora's value-its "intangible cultural heritage", characterized as "forms of cultural heritage that lack physical manifestation [and evoke] that which is untouchable, such as knowledge, memories and feelings” (Stefano, Davis, \& Corsane, 2012, p. 1).

As the rates of floristic decline indicate, the viability of intangible plant-based cultural heritage should be a concern in the region in conjunction with the traditional conservation aims of protecting living plants in their habitats. Referring to a global context, UNESCO (2003) acknowledges "oral traditions and expressions [...] social practices, rituals and festive events [...] knowledge and practices concerning nature” as intangible heritage priority areas. Considering the value of such heritage, I have been interviewing individuals in the Southwest since 2009 for their memories of flora. Recently in the form of ethnographic films, the interviews focus on the locales and species of resonance to the individuals, but with an ongoing emphasis on the kwongan, which includes the rapidly changing metropolitan Perth area. My interviewees are diverse in their attachments to Southwest plants; some are recently-landed tourists who have followed, in their caravans, the seasonal blossoming of wildflowers from Shark Bay to Esperance, whereas others have life-long, site-specific histories of physical, emotional, and spiritual attachment to flora. ${ }^{8}$ Where possible, the interviews occur in "the field"-for example, during wildflower walks, on the grounds of a botanical garden, or in the studio of an artist. Such field settings enable particular interactions between the interviewee, myself as ethnographer, and the plant-based prompts of seeds, leaves, flowers, roots, smells, tastes, sensations, artifacts, implements, and artworks.

\footnotetext{
${ }^{6}$ FloraCultures is an online archive that promotes the heritage of Western Australian plants through art, literature, music, historical writings, and oral histories. See http://www.floracultures.org.au.

7 FloraBase is an open access database of scientific information about all WA plant species. See https://florabase.dpaw.wa.gov.au.

${ }^{8}$ For a discussion of plant ethnography, see Ryan (2012) chapter 7.
} 


\section{A Material-Affective Theory of Botanical Memory}

In relation to this ethnographic practice, a material-affective theory of memory accounts for the bodily, sensory, emotional, and terrene (earthy) features of botanical recollection. In developing such a model, this section builds upon the work of Henry David Thoreau (1817-1862) and C. Nadia Seremetakis before briefly considering recent materiality and affect theory. Developed with reference to the American Northeast flora, Thoreau's botanical memory is conspicuous in his posthumous works. ${ }^{9}$ In particular, Thoreau (2000) crystallizes the nodes between materiality (of the plants themselves and related objects) and affect (of expressiveness, emotion, embodiment, sensoriality, and relationality). Thoreau conceived of these writings as a "Kalendar"-involving the documentation of the seasonal phenomena of Concord, Massachusetts, intermixed with historical, philosophical, and experiential reflections. His journal was a substrate for "material memory" (Peck, 1990, p. 45), hybridizing his personal recollections with those of other writers, both classical and contemporaneous. As a result, critics have characterized Thoreau's eco-literary corpus as "a project in memory" (Tauber, 2001, p. 69).

An entry from Wild Fruits presents a haptic recollection of Desmodium, a genus of plants in the pea family having the common name tick trefoil. The seedpod of Desmodium is known as a loment. Each seed is enclosed in a triangular sheath that readily detaches from adjoining seeds and bears barbed hairs to enhance its dispersal by clinging to animals. Thoreau recounts walking with a friend through a thick patch of trefoil along the Concord River, the "green scale-like seeds densely covering and greening our legs [and amounting] to a kind of coat of mail” (Thoreau, 2000, p. 159). With curiosity, humor, and amity, Thoreau's rendering is attentive to the materiality of the loment, the two men's clothes, and the ebbs and flows of walking: "It was the event of our walk, and we were proud to wear this badge” (Thoreau, 2000, p. 159). His companion's fervent devotion to the Velcro-like seed badge even "betrayed a certain religion about it" because when he "reappeared for a walk a day or two after, his clothes were nearly as well covered as at first” (Thoreau, 2000, p. 159).

In a similar tone, Thoreau recounts the explosive launching mechanism of witch hazel (Hamamelis virginiana) nuts through haptic and sonic remembrance. A witch hazel's woody fruit capsules rupture, releasing two dark glossy seeds as far as thirty feet away. Thoreau brings the "pretty clusters-clothed, as it were, in close-fitting buck-skin” (Thoreau, 2000, p. 190) into his chamber. "Three nights afterward I heard at midnight a snapping sound and the fall of some small body on the floor from time to time” (Thoreau, 2000, p. 190). The "bodies" were the stony seeds of the nuts casting themselves around-an ecological spectacle that continued for three days. This anecdote signifies the convergence of plant materiality (the reproductive strategies embodied in seeds) and affective human memory where fascination, respect, and delight predominate. Thoreau's affectedness represents a conception of plant materiality not as inert substance to manipulate but as animate matter to encounter dialogically: "I believe almost in the personality of such matter [...] can even worship it as terrene, titanic matter extant in my day [...] we healthily attract one another” (Thoreau, 2000, p. 168). His assertions prefigure Jane Bennett's notion of "vibrant matter" and the process she describes as "encountering a vital materiality [in which] all forces and flows (materialities) are or can become lively, affective and signaling” (Bennett, 2010, pp. 111, 117).

Although considerably different to Thoreau's nineteenth-century reflections, Seremetakis' "The Memory of the Senses” also begins with botanical encounter, specifically with the peaches of her native Greece. For

\footnotetext{
${ }^{9}$ See Thoreau (1993) and Dean (2000).
} 
Seremetakis, the content of memory is affected by the physiology of sensory experience-the "co-mingling" of memory and the senses-mediated by mneumonically-resonate things. She asks, "Is memory stored in specific everyday items that form the historicity of a culture, items that create and sustain our relationship to the historical as a sensory dimension?” (Seremetakis, 1996, p. 3). Seremetakis understands memory as a "material practice that is activated by embodied acts and semantically dense objects” (Seremetakis, 1996, p. 9). The emotional and historical imbrications borne by such objects "can provoke and ignite gestures, discourses and acts” (Seremetakis, 1996, p. 7). In other words, memory is latent and affective-its dimensions contingent upon, and instigated by, the materiality of objects. Sensory memories of flora—of nibbling, sniffing, scratching —are formed, evoked, and deepened through embodied encounters with living plants (such as the springing seeds of witch hazel) and related artifacts (the clothes one wears in a trefoil field or the trekking staff with which one gestures). However, despite its generative emphasis on memory and the senses, Seremetakis' conception is limited by a language of "objects" that elides the crucial mneumonic differences between living things (e.g., the gimlet tree) and inanimate artifacts (e.g., the gimlet staff). For example, this elision fails to recognize the agency of plants as intelligent beings that activate the memory of humans and nonhumans, while also themselves possessing the capacity for remembering (Gagliano, Mancuso, \& Robert, 2012, pp. 323-325).

In conjunction with the work of Seremetakis and Thoreau, affect theory offers a potential contribution to botanical memory-in which humans, plants, and objects reciprocally shape each other. Gregory Seigworth and Melissa Gregg characterize affect as the relational force of living bodies that "arises in the midst of in-between-ness: in the capacities to act and be acted upon” (2010, p. 1). Not simply the experience of emotion or feeling, affect denotes "forces of encounter" and the "ever-gathering accretion of force-relations" (Seigworth \& Gregg, 2010, p. 2, italics in original). Most significantly, an appreciation of affect stipulates recognition of the corporeality of relations in which bodies "co-participate in the passages of affect" (Seigworth \& Gregg, 2010, p. 2), whereby bodies perpetually affect and are affected. Affect is "persistent proof” (Seigworth \& Gregg, 2010, p. 1) of bodily immersion in world, environment, or habitat; in the trefoil field or witch hazel chamber. Therefore, memory is closely interwoven with the relational capacities that "belong to the doings of bodies" (Seigworth \& Gregg, 2010, p. 9). In this sense, botanical memory is in-becoming (resists being fixed or complete) and entails the interchange between remembering and being remembered. It emerges in the in-between-ness of vegetal and human bodies.

Alongside affect theory (with its concern for embodiment and relationality), the theorization of Seremetakis (with its emphasis on sensoriality), and the writings of Thoreau (that instantiate field-based memory), the "material turn" in anthropology (Hicks \& Beaudry, 2010), archaeology (Jones, 2007), cultural studies (Bennett \& Joyce, 2010a), and ecocriticism (Iovino \& Oppermann, 2014) merits consideration. The material turn dismisses the view of things as passive materials or symbolic structures, and instead recognizes the "distinctive forms of agency and effectivity on the part of material forces” (Bennett \& Joyce, 2010b, p. 4). In this light, Andrew Jones explores the production of memory through the materiality of artifacts (Jones, 2007). He argues against the prevailing notion of memory as a "storage container" assessed (or rejected) according to standards of authenticity or lucidity. Rather, memory is "sedimented" in our bodily actions; and material culture comprises embodied knowledge and extra-corporeal objects (Jones, 2007, pp. 9, 11-12). Despite Jones' disregard of the nonhuman through an emphasis on people and objects, his theory foregrounds the complex imbrications between memory and physical phenomena. Similarly, but with attention to trees, vegetables, fields, and other living agents, in her study of historical kitchen gardens in Europe, Jennifer Jordan addresses the 
generation of "edible collective memory" that involves the botanical world (Jordan, 2010).

\section{Let the Trees Do the Painting: Holly Story's Kino Art}

Concerned with the intertwining of memory and flora, this chapter turns now to interviews with Southwest Australians. Born in 1953 in Zimbabwe and immigrating to Australia in 1971, Holly Story is a visual artist and environmentalist who has intensively explored the use of indigenous flora—whole specimens, dyes, fibers, and resins-in her artwork. Holly's creative practice employs plant materials to investigate settler relationships to the WA environment, particularly its vegetation, which has been historically regarded in acutely polarizing terms: as beautiful and picturesque, as repulsive and worthless (Seddon, 2005). In reference to her exhibition Skin Deep (2006), Stephen Hopper remarks optimistically that "native plant pigments and their use in dyeing textiles may well signal closer intimacy with plant life from an old landscape” (Hopper, 2006, p. 9). Holly’s art centers around the Deep Creek locality near Walpole, on the South Coast of Western Australia, typified by tall open forests of karri (Eucalyptus diversicolor) and marri (Corymbia calophylla). She calls her work an "embodied practice" —and an "attempt to graft myself into the place"- through multisensorial experimentation with the plants of this vicinity. ${ }^{10}$

Holly's Deep Creek studio is nestled in the eucalypt forest with a sweeping western view across the D'entrecasteaux National Park to the Indian Ocean. In the spirit of Thoreau's cabin, she and her husband handcrafted their rustic hilltop retreat with a painstaking affection that speaks in the details: alcoves, nooks, a narrow staircase to a sleeping loft. After a short amble in search of the spring's first orchids, Holly shows me her latest work-in-progress, a series of paintings with marri gum. Also called kino, this astringent blood-red exudate is common to Eucalyptus trees but most profuse in the endemic marri from which it seeps then congeals to a dark amber-like substance. In the medicine of the Nyoongar of the Southwest, kino has been used externally for cuts, bites, and abrasions and internally for sore throats, diarrhoea, and scurvy (Clarke, 2008, p. 39). According to the nineteenth-century diarist George Fletcher Moore, kino is known as nalla in the Nyoongar language (Moore, 1842, p. 82). The gum of the endemic tree was an object of curiosity for WA explorers, settlers, and visitors. The mariner William Dampier (1651-1715) recorded his gustatory remembrance of kino while navigating the coast of Terra Australis: "The gum distils out of the knots or cracks that are in the bodies of the trees. We compared it with some gum dragon, or dragon's blood, that was aboard, and it was of the same colour and taste” (Dampier, 1703, p. 463). In the early twentieth century, novelist D. H Lawrence (1885-1930), during a visit to Perth, regarded the marri gum in macabre terms: "leaves and herbage underneath seem bestrewed with blood" and "this tree seems to sweat blood” (Lawrence \& Skinner, 1990, p. 93, as cited in Skinner, 1972, p. 112).

Holly's engagement with marri unveils the potential of kino while countering the predominant paradigm of artists manipulating natural materials to produce works. In this example, the trees do the art; the role of the artist is as facilitator, witness, and narrative guardian. In her studio, large unframed canvases are encrusted in maroon-colored gum layers of variable thicknesses. In line with Lawrence's remarks, the topography of kino splotches and splatters of the paintings does invoke blood and guts. The organic patterns provoke a visceral reaction as I feel the works decaying slowly into the soil between the marri roots outside the studio. In contrast, Holly radiates exuberance, playfulness, and respect as she conveys her initial encounter with kino as medium.

\footnotetext{
10 Story, interview, transcript.
} 
I was under one tree putting some paper out just to see what might happen. Then the gum dripped on my head! It was gorgeous. I put my hand up to receive the beautiful red drip. I have tasted the gum. It is sweet when it first comes out of the tree, then it becomes bitter. ${ }^{11}$

The memory of the sweet-bitter sensory transaction has inspired Holly's continued exploration of eucalypt kino as creative substance. "I'm now facilitating them making artworks by placing things under trees that drip a lot. In fact, some trees drip like taps”. ${ }^{12}$ In the co-produced paintings, the linkages between botanical memory (hers, mine, and her future audience's), affective modes (from Lawrence's dread to her wonder), and the kino's materiality (the manner in which its physical properties register through sight, touch, and taste) coalesce. Holly's work exemplifies the potential for memory to encompass dialogic, embodied encounters between people and plants. ${ }^{13}$

\section{A Feeling for the Material: Nalda Searles’ Balga Works}

An artist whose work integrates everyday objects into woven forms, Nalda Searles was born in 1945 in the arid Kalgoorlie-Boulder region of WA and presently lives near Perth. Nalda troubles the dichotomies of indigenous/introduced, cultural/natural, and subject/object through her investigation of the Australian environment during a thirty-five year career. Infused with personal and collective, familial and societal, and human and nonhuman memories, Nalda's art is sympathetic to the materialities of seeds, leaves, fibers, dyes, and "the bush". She comments, "my work reflects an awareness of the potential of plants. When I pick up things, because my skills are well-developed, I can almost straightaway identify how they can be used in acreative work". ${ }^{14}$ For Nalda, botanical memory links these materialities to the narratives of plants: "They have their own indigenous stories. They have colonial stories. They have my story and your story” ${ }^{15}$ Critic Ted Snell observes her "transformative practice that works with the poetry of materials to reveal what lies beneath the surface, literally and metaphorically” (Snell, 2009, p. 10).

Nalda's home studio is replete with previously exhibited works, intriguing found objects, organic miscellany, exhibition catalogues, and taxonomic guides, each instigating her memories as I point, ask, and listen. Her recollections meander between concepts that inspired works, people who were involved, particularly her mentor Pantjiti Mary McLean, ${ }^{16}$ and artistic techniques Nalda developed or adapted to facilitate the use of WA flora in textiles. Many artworks were gestated during the eight-hour drive from Perth to Kalgoorlie. Motioning toward Mallee Leaf Jacket (1996), a salvaged tweed jacket embroidered with eucalyptus leaves, she explains,

I keep my sharp eye out. I've made that drive at least a hundred times. If there's a storm, a whole branch comes down. If I can reach it, I stop, drag it out of the bush, and put it in the car. Then I have this fresh material. When I get something like that, I need to use it straight away. ${ }^{17}$

Nalda conveys her experience in the present tense, signifying that the memory is not quarantined to the

\footnotetext{
11 Story, interview, transcript.

12 Story, interview, transcript.

13 Holly Story's other work similarly exemplifies the spectrum of modes and practices that could be included within botanical memory. See for example, Fancywork (2000).

14 Searles, interview, transcript.

15 Searles, interview, transcript.

16 The Aboriginal artist Pantjiti Mary McLean was born in 1930 in Kaltukutjarra, Docker River, WA.

17 Searles, interview, transcript.
} 
past, but inheres within current moments and future prospects. The Shape Changers Slippers (1997), a pair of felted slippers covered in sandalwood (Santalum spicatum) sawdust, materializes a memory of her father:

I had his slippers from when he died. He used bits of rubber called bowyangs to hold the slippers on his feet; old men used to do that. Later in his life, he bought a lathe and went bush, like a lot of fell as his age, to collect sandalwood pieces. He'd always offer me the sawdust, which I hoarded. ${ }^{18}$

Despite the panoply of mneumonically-laden objects in Nalda's studio, balga bracts—glistening uncannily like an array of dead cockroaches_cordon my attention. Known historically as grasstree and blackboy, balga is the Nyoongar name for Xanthorrhoea preissii, a tree-like monocot endemic to the Southwest. Bearing tall and thin flowering spikes, balga exhibits grass-like foliage. Its bracts-the specialized leaves of the inflorescence-are dark brown and large. Blackboy is an antiquated name that reflects the settler-era likening of the plant to the distant image of an Aboriginal person. The species has been used extensively: for example, dead flowering stalks for spear-making, living flower stalks for a fermented drink, and resin applied as an adhesive (Ryan, 2012, p. 140). On setting up camp during an excursion with Nyoongar guides, Moore commented in 1831, "blackboy poles are stuck in the ground [...] these are covered with grassy tops of the blackboy: it is a good temporary shelter in rain” (Moore, 1834, p. 95). In comparable language, during the 1930s, composer Thomas Wood personified the tree as "that strange fascination [...] wearing a mop of tousled grass overtopped by a spear” (Wood, 1938, p. 105).

The use of balga bracts in textile art invokes personal and collective memories of the plant's cultural significance. For instance, Balga Blanket (1995-2008) is a large woolen blanket covered in more than three-thousand bracts. Known as appliqué, the technique involved the production of rectangular patterns through the stitching of bracts to the blanket. ${ }^{19}$ Another example of appliqué, Xanthorrhoea Dress (1996) is a brown woolen gown clothed in bracts and eventually subsumed within the work Kangaroo Couple (1995-2008). ${ }^{20}$ Made by the artist's mother in 1975, the gown was worn by Nalda for twenty years until its creative appropriation. Similarly sheathed in bracts, Whiteboy Blazer (1996) projects the "colonial connotations" of her work through its satirical play on the obsolete name blackboy. ${ }^{21}$ Regarding the application of bracts to textiles, Nalda notes her need "to go inside the plant. I had to put the plant on me to get a feeling for the material. I had already been making big baskets from local flora, but I never stitched plants onto clothing. The idea hit me like a bolt during a drive to Kalgoorlie." ${ }^{22}$ Her tactile use of balga stimulated a distinctly creative period. "I made Balga Blanket during this time. I took a whole double-bed blanket and covered it with balga. I stitched on the bracts”. ${ }^{23}$ As mneumonic objects, the bract-based textile works are permeated with the affective registers of balga — a protective plant providing warmth, nourishment, identity, and spiritual meaning to people for millennia.

\section{Bitter Tastes, Sweet Smells: Kevin Collins’ Banksia Mneumonics}

In 1984, Kevin Collins and his family purchased the "bare grass paddock" in Mount Barker, WA, that

\footnotetext{
18 Searles, interview, transcript.

19 To view Balga Blanket, see http://artsearch.nga.gov.au/Detail.cfm?IRN=236056.

20 To view Xanthorrhoea Dress, see http://searlesartist.blogspot.com/.

${ }^{21}$ Searles, interview, transcript.

22 Searles, interview, transcript.

23 Searles, interview, transcript.
} 
would later become Banksia Farm, comprising an arboretum, botanical art gallery, and stone guesthouse. ${ }^{24}$ Three years on, they had planted nearly half of the known species of banksias (Banksia spp.).

We thought to ourselves, "we have thirty species and there’s only seventy-six [now seventy-eight]. Let’s keep going”. We flew to Queensland in 1991 to get the last one, which grows on Hinchinbrook Island. We added new banksias discovered in 2000 and 2007 to complete the collection. ${ }^{25}$

Known for their prominent inflorescences, these shrubs and small trees are quintessentially Australian; only one (B. dentata) occurs naturally outside of the nation and $80 \%$ of all species grow only in the Southwest (Collins, Collins, \& George, 2009, p. 32). In addition to their role as a food source for native vertebrates and invertebrates, banksias are economically vital to the cut-flower and wildflower tourism industries.

As conspicuous members of the Southwest bush, banksias also pervade the botanical memory of past and present. For instance, named poolgarla in Nyoongar, bull banksia (B. grandis) has been used ethnobotanically for an array of purposes, including to make a fermented beverage (flowers) and to transport smouldering coals (stalks) (Daw, Walley, \& Keighery, 1997, p. 40). During his visit to the King George Sound area, the physician Isaac Scott Nind (1797-1868) confirmed "every individual of the tribe, when travelling or going to a distance from their encampment, carries a fire-stick [...] It is generally a cone of Banksia grandis, which has the property of keeping ignited for a considerable time” (1979, p. 21). Moreover, during his 2000-mile traverse of the coastline from Adelaideto Albany, the explorer Edward John Eyre (1815-1901) observed, with palpable affect, "the appearance for the first time of the Banksia, a shrub which I had never before found to the westward of Spencer's Gulf [an inlet in SA], but which I knew to abound in the vicinity of King George's [sic] Sound” (1845, p. 14), the end point of his calamitous expedition. His "eagerness and anxiety" were assuaged by the "degree of satisfaction" he experienced on first spotting banksias (1845, p. 14). The trees indicated a landscape change, marked his advance to Albany, and hence signified the hope of salvation from grim circumstances (mutiny, starvation, extreme thirst).

In the visitors' center, Collins invokes these sorts of historical narratives as he adroitly selects an object from his table of vegetal paraphernalia: a Banksia grandis cone studded with the woody lips of dehiscent follicles (or dry fruits). He expounds on the physical properties vis-à-vis Nyoongar understandings of the cone.

It's the heaviest banksia cone and has excellent qualities. It is very hard. The outer layer smoulders. Aboriginal people transported their campfire with it. In a fresh state, the flowers contain tons of nectar for birds and possums. Aboriginal people made nectar drinks by immersing its flowers in water. (Eyre, 1845, p. 14)

When I ask him about the palatability of its seeds, Collins squinches his face then furrows his brow, revealing the ineradicable imprint of a gustatory memory. "When I first tried a B. grandis seed, I spit it out because it was too bitter. However, most banksia seeds are quite pleasant, at least to my palate. In fact, only a couple taste bitter" (Eyre, 1845, p. 14). Such embodied memories are essential to Collins' instructional approach; he presents his recollections of contact with banksia to foster visitors' memories through the plants' material presence.

During the interactive exposition, Collins tracks seamlessly between sensory memory, banksia physiology, and corporeal immediacy. He peers studiously at the follicle of another banksia. "It is only attached by a small cord to the flower head. You can pop out the follicle with your fingers. Expose it to high heat to get it jumping

\footnotetext{
${ }^{24}$ Collins, interview, transcript.

${ }^{25}$ Collins, interview, transcript.
} 
like popcorn. That will release the seeds" (Eyre, 1845, p. 14). He encourages me to engross myself sensorially—without inhibition. "Feel the texture. See the old flower heads? If you squeeze them, you will feel the follicles underneath. The structure is very dense with a strong protective layer, indicating that this species must have fire to release seeds” (Eyre, 1845, p. 14). Further along, human-plant menumonics involve the interlacing of taste, touch, and smell. "This flower smells sweet but you have to put your nose into it. As kids, we would part the flowers, poke our tongues in there, and suck the delicious nectar" (Eyre, 1845, p. 14). Regarding another banksia's inflorescence, Collins effuses, "when you squeeze them, little balls of nectar should appear. There's one in the middle there! Just chew the whole flower. You will get some of that nectar!" (Eyre, 1845, p. 14).

\section{Conclusion}

During field interviews, material prompts (follicles, bracts, kino, and derived objects) activate botanical memory to a degree that would not be possible otherwise. The multisensorial prompts-both living and inanimate, all "vibrant matter"- discussed in this chapter enable Ian Smith, Holly Story, Nalda Searles, and Kevin Collins to not only recount (bring to mind) but to enact (form new, or deepen) their memories of Southwest flora. These extracts demonstrate that botanical memory is "sedimented" (echoing Jones) in the articulations between plants, people, and objects. Affectively rich and materially referential, botanical memory also engages empirical understandings of plants, such as the structural characteristics, biogeographical distributions, ecological dynamics, and ethnobotanical dimensions of species. These intricate mneumonic narratives are not recited by the interviewees as a series of matter-of-fact, chronologically arranged observations. Instead, their stories are marked by corporeal, spatial, and temporal interpenetrations that reach across the past, present, and future while blurring the ontological categories of human, plant, and environment. From these interviews, it is further evident that the proximate senses strongly underlie affective memory. Sucking banksia nectar, touching balga bracts, tasting marri kino, and grasping the gimlett staff are corporeal actions with mneumonic resonance. And, in this material-affective sense, the exploration of plant-based human memory has never been more timely. In an era of catastrophic species loss, the process of remembering becomes intrinsically linked to the act of conserving.

\section{References}

Bennett, J. (2010). Vibrant matter: A political ecology of things. Durham, NC: Duke University Press.

Bennett, T., \& Joyce, P. (Eds.). (2010a). Material powers: Cultural studies, history and the material turn. New York: Routledge.

Bennett, T., \& Joyce, P. (2010b). Material powers: Introduction. In Material powers: Cultural studies, history and the material turn (pp. 1-21). New York: Routledge.

Clarke, P. A. (2008). Aboriginal plant collectors: Botanists and Australian aboriginal people in the nineteenth century. Dural Delivery Centre, NSW: Rosenberg Publishing.

Collins, K., Collins, K., \& George, A. (2009). Banksias. Melbourne: Blooming Books.

Dampier, W. (1703). A new voyage round the world (Vol. 1). London: James Knapton.

Daw, B., Walley, T., \& Keighery, G. (1997). Bush tucker plants of the South-West. Kensington, WA: Department of Environment and Conservation.

Eyre, E. J. (1845). Journals of expeditions of discovery into central Australia and overland from Adelaide to King George's sound. London: T. and W. Boone.

Gagliano, M., Mancuso, S., \& Robert, D. (2012). Towards understanding plant bioacoustics. Trends in Plant Science, 17(6), 323-325. doi: 10.1016/j.tplants.2012.03.002 
Gole, C. (2006). The southwest Australia ecoregion: Jewel of the Australian continent. Wembley, WA: Southwest Australia Ecoregion Initiative.

Hicks, D., \& Beaudry, M. C. (Eds.). (2010). The Oxford handbook of material culture studies. Oxford: Oxford University Press. Hopper, S. D. (2006). Developing through art a botanical and landscape context in a settler society. In Holly Story: Skin deep (pp. 4-9). Melbourne: SPAN Galleries.

Hopper, S. D., \& Gioia, P. (2004). The Southwest Australian floristic region: Evolution and conservation of a global hotspot of biodiversity. Annual Review of Ecology, Evolution, and Systematics, 35, 623-650. doi: 10.1146/annurev.ecolsys.35.112202.130201

Iovino, S., \& Oppermann, S. (Eds.). (2014). Material ecocriticism. Bloomington, IN: Indiana University Press.

Jones, A. (2007). Memory and material culture. Cambridge, UK: Cambridge University Press.

Jordan, J. A. (2010). Landscapes of European memory: Biodiversity and collective remembrance. History and Memory, 22(2), 5-33.

Lambers, H., \& Hopper, S. D. (2014). Introduction. In H. Lambers (Ed.), Plant life on the sandplains in Southwest Australia: A Global biodiversity hotspot. Crawley, WA: The University of Western Australia Press.

Lawrence, D. H., \& Skinner, M. L. (1990). The Cambridge edition of the works of D. H. Lawrence: The boy in the bush. P. Eggert, (Ed.). Cambridge, UK: Cambridge University Press.

Moore, G. F. (1834). Extracts from the letters and journals of George Fletcher Moore. M. Doyle, (Ed.). London: Paternoster Row.

Moore, G. F. (1842). A descriptive vocabulary of the language in common use amongst the aborigines of Western Australia. London: W.M.S Orr and Paternoster Row.

Myers, N., Mittermeier, R. A., Mittermeier, C. G., da Fonseca, G. A., \& Kent, J. (2000, February 24). Biodiversity hotspots for conservation priorities. Nature, 403(6772), 853-858.

Nazarea, V. (1998). Cultural memory and biodiversity. Tucson: University of Arizona Press.

Nind, I. S. (1979). Description of the natives of King George's sound (Swan River Colony) and Adjoining country. In N. Green (Ed.), Nyungar-The people: Aboriginal customs in the Southwest of Australia (pp. 15-55). North Perth, WA: Creative Research.

Pate, J. S., \& Beard, J. S. (Eds.). (1984). Kwongan, plant life of the sandplain: Biology of a Southwest Australian shrubland ecosystem. Nedlands, WA: The University of Western Australia Press.

Peck, H. D. (1990). Thoreau's morning work: Memory and perception in a week on the Concord and Merrimack Rivers, the Journal, and Walden. New Haven, CT: Yale University Press.

Ryan, J. C. (2012). Green sense: The aesthetics of plants, place and language. Oxford: True Heart Press.

Ryan, J. C. (2014). Being with: Essays in poetics, ecology, and the senses. Champaign, IL: Common Ground Publishing.

Seddon, G. (2005). The old country: Australian landscapes, plants and people. Cambridge, UK: Cambridge University Press.

Seigworth, G. J., \& Gregg, M. (2010). An inventory of shimmers. In The affect theory reader (pp. 1-15). Durham, NC: Duke University Press.

Seremetakis, C. N. (1996). The memory of the senses, Part I: Marks of the transitory. In The senses still: Perception and memory as material culture in modernity (pp. 1-18). Chicago, IL: University of Chicago Press.

Skinner, M. L. (1972). The fifth sparrow: An autobiography. Sydney, NSW: Sydney University Press.

Snell, T. (2009). Foreword: Nalda Searles: Experience, skill, memory and engagement. In A. Nicholls (Ed.), Nalda Searles: Drifting in my own land (p. 10). Middle Swan, WA: Nalda Searles and ART ON THE MOVE.

Stefano, M., Davis, P., \& Corsane, G. (2012). Touching the intangible: An introduction. In Safeguarding intangible cultural heritage (pp. 1-5). Woodbridge, UK: Boydell \& Brewe.

Tauber, A. (2001). Henry David Thoreau and the moral agency of knowing. Berkeley: University of California Press.

Thoreau, H. D. (1993). Faith in a seed: The dispersion of seeds and other late natural history writings. Washington, DC: Island Press.

Thoreau, H. D. (2000). Wild fruits: Thoreau's rediscovered last manuscript. Dean, B., (Ed.). New York: W.W. Norton \& Company.

UNESCO. (2003). Convention for the safeguarding of the intangible cultural heritage. Paris: UNESCO.

Wood, T. (1938). Cobbers: A personal record of a journey. London: Oxford University Press. 